

\title{
Soil Classification Using Image Processing and Modified SVM Classifier
}

\author{
Priyanka Dewangan, Vaibhav Dedhe \\ Department of Electronics and Telecommunication Engineering, \\ Shri Shankaracharya Institute of Technology \& Management, Bhitauna, Uttar Pradesh, India
}

\begin{abstract}
Recently the use of soil classification has gained more and more importance and recent direction in research works indicates that image classification of images for soil information is the preferred choice. Various methods for image classification have been developed based on different theories or models. In this study, three of these methods Maximum Likelihood classification (MLC), Sub pixel classification (SP) and Support Vector machine (SVM) are used to classify a soil image into seven soil classes and the results compared. MLC and SVM are hard classification methods but SP is a soft classification. Hardening of soft classifications for accuracy determination leads to loss of information and the accuracy may not necessary represent the strength of class membership. Therefore, in the comparison of the methods, the top $20 \%$ compositions per soil class of the SP were used instead. Results from the classification, indicated that output from SP was generally poor although it performs well with soils such as forest that are homogeneous in character. Of the two hard classifiers, SVM gave a better output than MLC.
\end{abstract}

Keywords: Soil Classification, Image Processing, Support Vector Machine, SVM

\section{INTRODUCTION}

It is an undeniable statement that 'land is an important asset and a means to sustain livelihood'. It is the key resource for most human activities including forestry, agriculture, industry, mining, etc. Land is therefore a fundamental factor of production closely linked with the economic growth of a nation and its people[1]. However, as the population increases, demand for land for use in settlement, construction of

infrastructure, farming (agriculture) and other human activities also increases.

Satisfying as a result, land and its associated natural resources like forest, vegetation, etc are being subjected continually to changes and these changes in turns affect the ecosystem. Even water resources like rivers, streams and wetlands that may be found in areas where such activities occur are also affected. For example, when changes occur in vegetation; wildlife habitat, fire conditions; aesthetic and historical values and ambient air quality, are all affected.

As human and natural forces are transforming the landscape, resource agencies find it increasingly important to monitor and assess these alterations. Land use and soil is therefore regarded as the single most important factor of environmental change such as deforestation, habitat fragmentation, urbanization, and wetland degradation. Soil deals with the physical features or vegetation as evident on the land whereas land use is about what economic activity or use the land is put to Research in land use. Soil studies have generated so much interest locally and internationally due to concerns globally on land use. Soil changes and its consequences to the environment. It has therefore become one of the crucial elements in images classification for scientific research and reallife earth science applications[2]. One of the fundamentals required for such studies are maps. Various methods are used for the production of these maps, however, the application of remote sensing for map production is increasing become the relatively cheap and quick method of acquiring up-to-date information over a large geographical area. Conventional ground survey methods of mapping are 
labour intensive, time consuming and are done relatively infrequently[3]. Especially in fast changing environments, maps produced using ground survey methods will soon become obsolete with passage of time.

\section{PROBLEM IDENTIFICATION}

Cryptography The availability of up-to-date land use soil information is central to much resource management, planning and monitoring programmes. Maps are fundamental for the provision of such land use - soil information and processes that enhances or leads to the production of such current maps in a costeffective manner is essential. Recent direction in research works indicates that classification of satellite images for soil information is the preferred choice for producing such maps.

Out of the many methods for image classification, three were chosen Maximum Likelihood Classification, Sub-pixel Classification and Artificial Neural Network Classification[3]. In this work, support vector machine is chosen because they provide a varied of options, good for comparison as;

1. Maximum Likelihood is a supervised parametric hard classifier.

2. Sub-pixel Classification is a supervised nonparametric soft classifier.

3. Artificial Neural Network Classification is a supervised non-parametric hard classifier.

The focus of this project is to explore the capabilities of the selected methods (Maximum Likelihood Classification, Sub-pixel Classification and Neural Network Classification) to effectively represent soil types.

\section{METHODOLOGY} Image Pre-Processing

Image pre-processing are actions or processes undertaken prior to the main data analysis and extraction of information. They are of two main forms - radiometric correction or geometric correction. Radiometric corrections are needed to correct the data for sensor irregularities and unwanted sensor or atmospheric noise, and converting the data so they accurately represent the reflected or emitted radiation measured by the sensor[4].

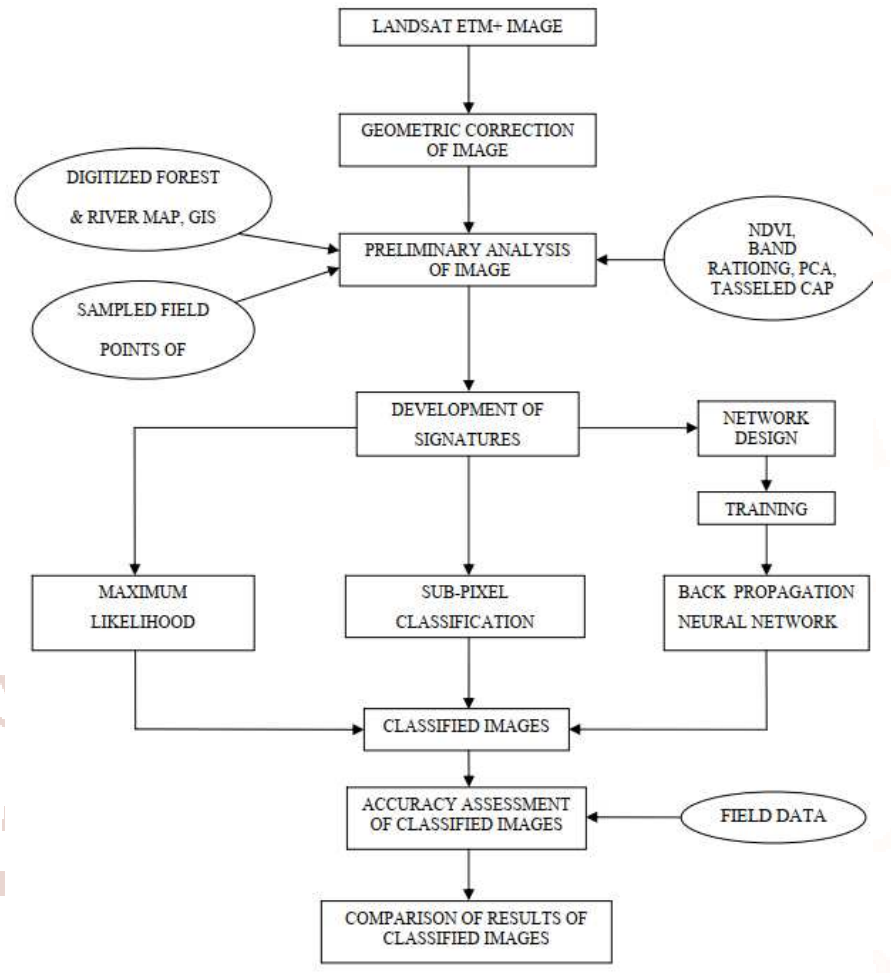

Figure 1: Fundamental Structure of soil classification process

\section{Radiometric Correction}

It has been identified above; radiometric corrections are important and mandatory when using multi-date images datasets. This must be done so that images obtained by sensors at different times are made comparable in terms of radiometric characteristics. Techniques like image enhancement, normalization, calibration etc have been applied to multi-date satellite images to increase the amount of information for improve interpretability. In this study however, no atmospheric correction was applied because data on atmospheric characteristics was not available. Secondly only a single-date image is being used for the classification and therefore atmospheric correction can be ignored.

\section{Image Processing}

In remote sensing, images are historically processed digitally because of two important principal areas of application namely; the improvement of the spectral information to enhance the process of visual interpretation and the processing of image data for computer assisted classification. The aim of both processes is to increase spectral separability of the object features in the image.

Commonly used image enhancement techniques include image reduction, image magnification; transect extraction, contrast adjustments (linear and 
non-linear), band rationing, spatial filtering, Fourier transformations, principal components analysis, and texture transformation (Jensen, 1996). Two of these techniques; Vegetation Indices developed under the band rationing technique and Principal Components Analysis will be considered briefly as they were used in this study.

\section{Image classification using Support vector Machine}

Support vector machine (SVM) in machine learning are supervised models associated with respect to learning algorithms. These are mainly used for analysing the data for regression and classification. For a set of training examples, it belongs to either one of the two categories; a support vector machine algorithm for training generates a model which tells the new thing falls in to which category by a nonprobabilistic binary classifier. SVM model is the example on depiction of points in space which is mapped. Thus, the data of different types are separated by as wide as possible. The new data are mapped and categorized according to which part of the group they fall on. Support Vector Regression: Developed by Vapnik (1998).

\section{RESULTS}

The image dataset used are clay, Clayey Peat, Clayey Sand, Humus Clay, Peat, Sandy Clay, and Silty Sand. Out of this database two images from each are shown in figure 2 .

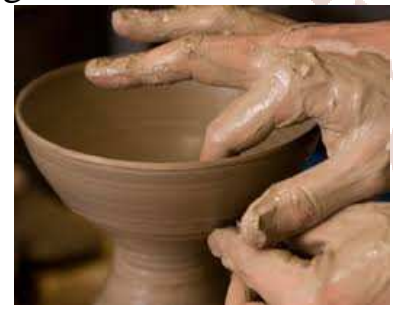

(a)

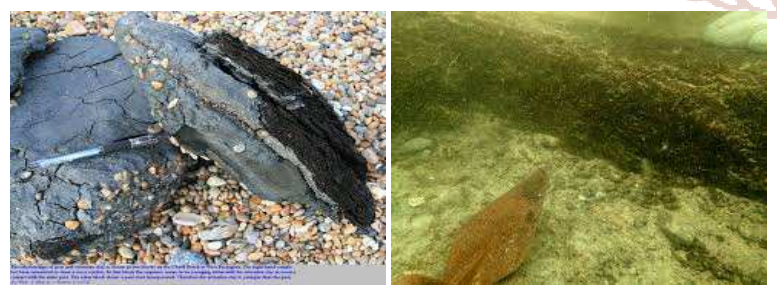

(b) Clayey Peat

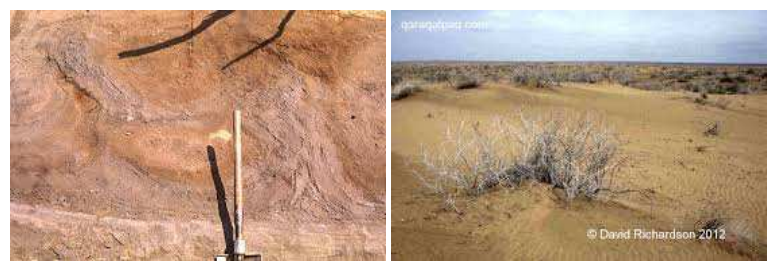

(c)

Clayey Sand

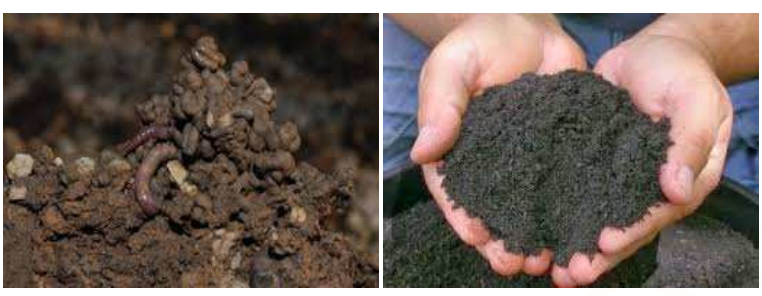

(d) Humus Clay



(e)



Peat
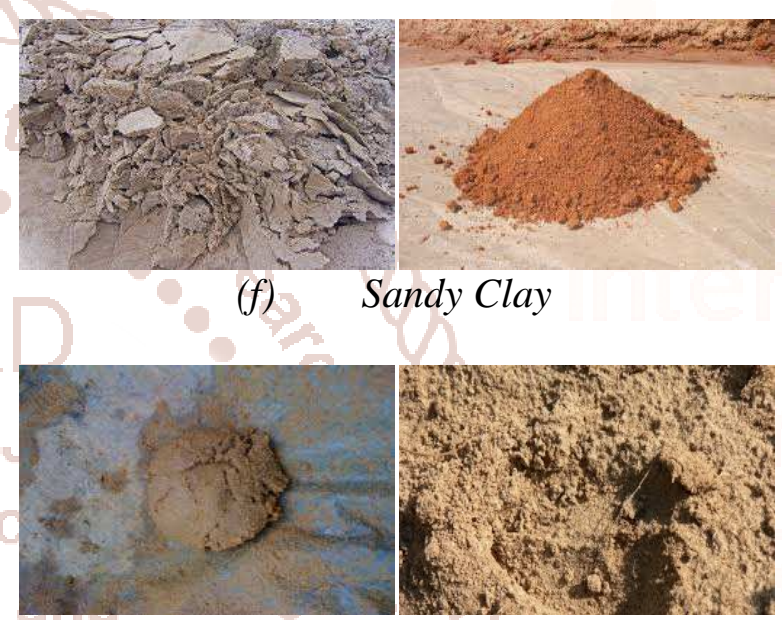

(g) Silty Sand

Figure 2: Soil classification database

The algorithm proposed here may have significant improvement over some of the other past soil classification systems.

Binary classification: binary classifier (Table:1) is used to govern whether the soil type is sandy or not. Support vector machine (SVM) do the classification of the non-sandy soil. The soil types are better classified here Majority of the misclassified objects are relayed near to the segment line. Near the segment boundary Measurements spotted as often noisy and thus can be decided that the enactment of the classifiers was excellent.

\begin{tabular}{|l|l|l|}
\hline Soil class & $\begin{array}{l}\text { Percentage of } \\
\text { correctly } \\
\text { classified } \\
\text { segments }\end{array}$ & $\begin{array}{l}\text { Percentage } \\
\text { of correctly } \\
\text { classified } \\
\text { instances }\end{array}$ \\
\hline Sandy soil & 100 & 96.6 \\
\hline Non-sandy soil & 100 & 99.5 \\
\hline Total & 100 & 97.8 \\
\hline
\end{tabular}




\section{CONCLUSION}

These Different techniques has been used and SVM classifier is found to outperform over all other techniques.

\section{REFERENCES}

1. F. Ellis, "The Determinants of Rural Livelihood Diversification in Developing Countries," $J$. Agric. Econ., vol. 51, no. 2, pp. 289-302, Nov. 2008.

2. H. Nagendra, D. K. Munroe, and J. Southworth, "From pattern to process: landscape fragmentation and the analysis of land use/land cover change," Agric. Ecosyst. Environ., vol. 101, no. 2-3, pp. 111-115, Feb. 2004.

3. H. Yuan, C. Van Der Wiele, and S. Khorram, "An Automated Artificial Neural Network System for Land Use/Land Cover Classification from Landsat TM Imagery," Remote Sens., vol. 1, no. 3, pp. 243-265, Jul. 2009.

4. T. M. Lillesand and T. M. Lillesand, Remote sensing and image interpretation. 2003.

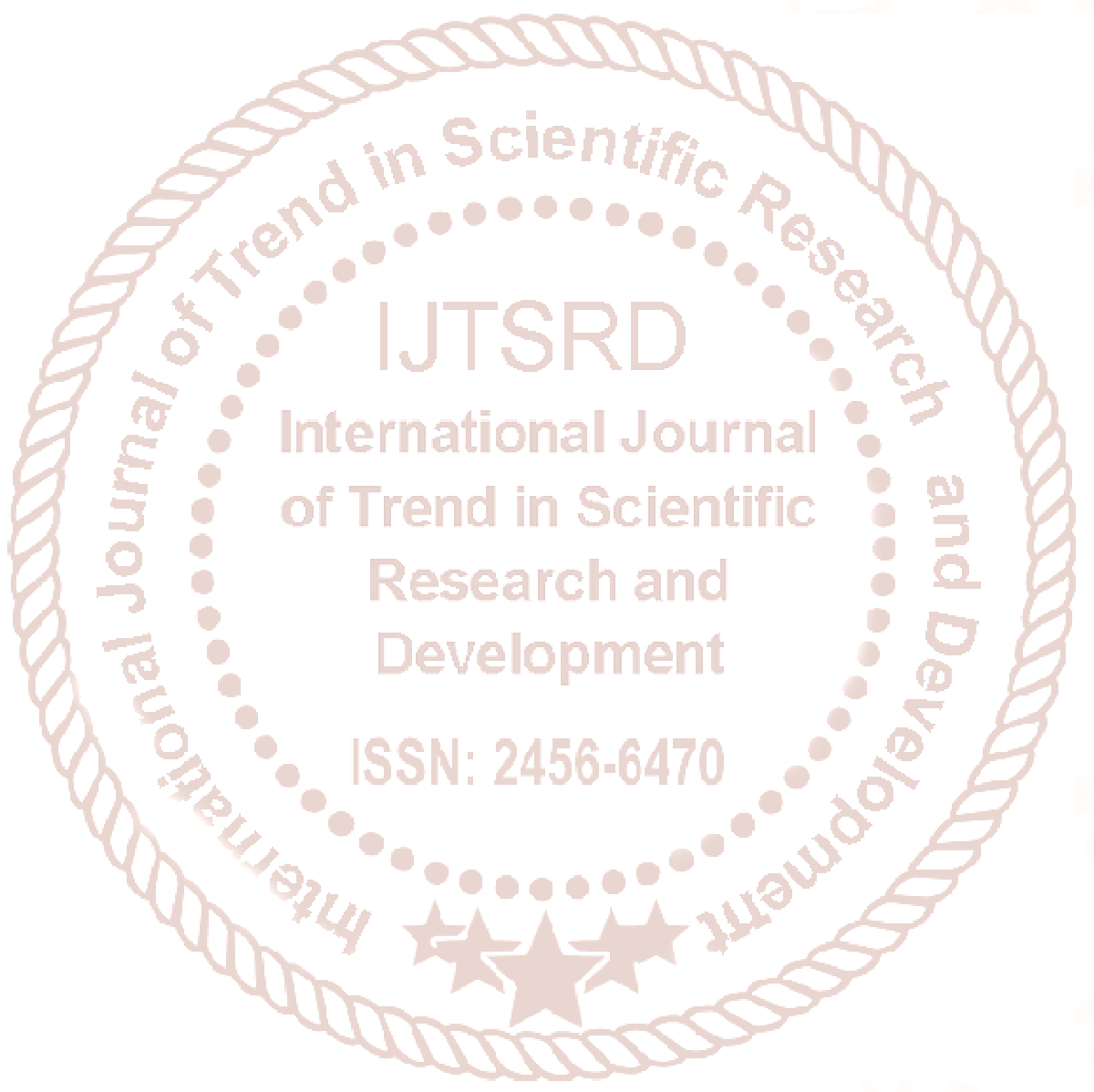

